\title{
The Exploration and Practice for Research Experiment Teaching Based on Project
}

\author{
Meng Wang, Jianqiang Wu, Yan Li \\ School of Electrical Engineering and Automation \\ Harbin Institute of Technology \\ Wangmeng1980@hit.edu.cn
}

Keywords: Experiment teaching; Exploration and Practice; Research Experiment Project; Elite Education

\begin{abstract}
This paper proposes a new experiment teaching mode. It is a kind of elite education idea and way. The research experiment projects were employed to the course in this mode. Students don't have to complete the traditional experiment projects in the learning of this course. They can gain the score and credit by completing a full research experiment project. The research projects are come from their teacher's research projects and some enterprise's engineering projects. And the projects should be interest, intuitiveness, practicality, comprehensiveness, innovation and some other characters. The difficulty is that it should be required to match the level that the college students electronic designing competition. This new experiment teaching mode has been prepared from spring semester in 2011 and about 160 students were selected to take part in the new experiment teaching mode in the spring semester in 2012. The learning effectiveness was compared between the students who learned in the new mod and the students who learned in the traditional mode. The result shows that more students learned in the new mode got higher scores in the similar examination paper. What's more, the students learned in the new mode show more flexibility in analyzing and resolving problems. They can resolve the problem better and faster than the other students.
\end{abstract}

\section{Introduction}

The National Middle and Long Term Education Reform and Development Planning Summary proposed that 'speed up the building of world class and high level university, and train a group of innovative talents'. [1] The world class university's core mission and top priority is training the innovative talents. In the process of building a world class university, the Harbin Institute of Technology as a research university, implements strategy of training excellent talents in the talent cultivation. And improve educational and teaching reform, implements quality engineering undergraduate teaching. One of the important task of training excellent talent is that optimize the design of scientific and technological innovation activities, open the laboratories and research centers further, strengthen the training of students' research project and create a open and academic communication atmosphere. [2,3]

There is a strict engineering training tradition in our university. In order to add the color of science and technology innovation to the tradition, the experimental teaching has been raised to an important position in our university, and it has been regarded as a key educational reform. The experimental education has taken up a rapid development stage for the past few years. It contains building experiment platform, strengthening the education of science and technology innovation experiments, training the students' design capability, engineering practice and comprehensive innovation ability. [4]

Electronics experiment is an important part of electronics curriculum system and is its experimental teaching. The purpose of the course is strengthening the understanding of the basic theory knowledge, training the testing technology and ability of operation, the preliminary ability of scientific research and innovation, and the ability to analyze and solve problems. [5] In order to strengthen the function of the practical teaching and make sure students in different levels get 
practice and innovation ability training relevantly. Especially, for the cultivation of top students, the comprehensive research experiment teaching system is needed. This requires the electronics experimental teaching mode to be adjusted and reform constantly. The new mode of electronics experiment----the exploration and practice for research experiment teaching based on project was build based on this purpose. Students can be trained in three aspects by complete a full research project. First, students can strengthen the knowledge of the basic knowledge of electronic technology application that learning and innovation needed in the future. And the second, it can improve students' practical ability and innovative consciousness. And the final purpose is to lay a solid foundation for the learning when they come into the professional stage and the innovation activities [6, 7].

\section{The content of the new experiment teaching mode}

The content of the new experiment teaching mode is to build a new experiment teaching mode. In this experiment teaching mode, students should not have to complete the traditional electronics experiment project. They can get the scores and credits by completing a complete research project. The research experiment teaching based on project is different from the traditional experiment, and its feature is scientific research. The students who take part in this new teaching mode can make sure the content of project themselves. And then discuss it with their learning advisor. If the advisor agrees with the students' idea, then the student can start the further study. Otherwise the learning advisor can recommend some projects which can be come from their research project or designed a suitable project for the students separately for the students to select. The level of the difficulty should catch up that of the national college student electronic competition. And the content of the project should be relatively to the green power industry. This new teaching mode is suitable for the elite talents and it service for a few top students. The content of the project is interesting, intuitive, practicality, comprehensive and innovation. In the process of completing a complete project, students put forward the project, determine the program, set the technical parameters, choose and use the instrument and the device, debug the hardware circuit and realize the function. So, the ability to use the knowledge comprehensive, the practical ability and the engineering practice ability could be improved.

\section{Constructing an open innovation hardware platform}

Constructing an open innovation research laboratory is necessary in this new experiment teaching mode. The laboratory should be fit for innovation and the equipment should meet the requirements of the innovation research experiments. What's more, it should be an open laboratory. So the students can use it conveniently.

The laboratory is established based on the electrical and electronic experimental teaching center. The equipments and experimental facility in the laboratory are the most advanced equipment in the center. Most of the equipments and instrument are offered by Agilent Technologies Inc such as the oscilloscopes, signal sources and digital multimeters.

The laboratory is opened to the students freely. Students can choose any content of project, use any equipments and components, and enter into the laboratory any time. They can also enter into the laboratory to learn and research freely through the network management system (NNS). The NNS include the power management of the experiment table and the learning record of the students. The power management can make sure the experiment table which students study on have power and the others not. This can ensure the electricity safety and save energy. The learning record of the students can be used for the course evaluation. The open lab is opened from Monday to Sunday. And the open time is from 8:00 to 21:30.

\section{Formulate a suitable teaching syllabus and construct a teaching team}

The purpose of this course is responded to the target of building a world class university and 
implementing elite education. It combines the basic experiment based on the theoretical courses with the research experiment and is a new experiment teaching mode. It provides a choice of further learning for the students who have a solid theoretical basis and the structure of knowledge, excellent at practical ability and creative potential. The course is build for the few elite talent.

The students learned in this course should complete a certain amount of basic experiment projects, and then complete a full research project by using most of the class hours. This can make sure the students gain basic experiment practice and the chance of further study. In process of the basic experiment study the students should learn the method of application of the instrument and meter, Such as oscillometer, multimeter, signal source, dc power supply and some other instruments and meters. The students can make preparations for the measurement of the future projects debugging. Some basic circuit principle should also be learned. This can be improved the understanding of the basic knowledge of the theoretical courses. When the students who learn in this new teaching mode completed the basic content learning, they can take part in the research project study. And they will complete the project by a whole year or more. They may seek help from their advisors. Sometimes, they find that they can only get some necessary advices. They should learn how to solve the problems themselves. So it is beneficial for teaching students accordance of their aptitude and personalized.

The course has 90 class hours and 5 credits. The 15 class hours are for the basic experiments and the 75 class hours is for the research projects. The basic experiment is like the traditional experiments. And 60 research projects are prepared for the students who take this course to choice. It involved the switching power supply, wind energy, solar energy, Li-ion battery and some other field of the new energy resources.

Constructing a stable, technology exquisite, structure optimization and innovation practice experimental teaching team is one key part of the curse. The team is constituted of full time laboratory teachers mainly, together with basic and professional teachers. And the doctoral and the master are encourage to act as teaching assistant. The team is suit for the students with different interesting and different special talents. It offers teachers for building a scientific researching teaching environment. The team is consisted of 19 professors or associate professors and 17 lecturers. There are about 20 masters and doctors assisted guidance the students. The students will be divided into some g teams, one team may include three to five students. A team has a complete research project that is different to any others. One professor should tutor a team or two. Due to the project will relative to much field of science, the learning advisor should come from different professional field. The masters and the doctors should come to the open lab and give some guidance within their capabilities.

\section{The mechanism of how to select the students and evaluation mechanism}

The new teaching mode is build for the top students. And it is only suit for a few students. The mechanism how to select the students should be established.

The students who want to join the curse should submit an application in the beginning of semester. The application should contain the academic record of the curse before. What is more, it should contain the practical experience that he/she has taken over.

The students who will take this curse will be selected by an oral quiz. And the practice experience in the application will be regarded as an important reference. And the electrical and electronic experiment teaching centre will build a defense committee to select the top students.

The basic content included the method of the application of the instruments and meters, the basic circuit principle, and the method of the application of some components. This section takes about $40 \%$ of the whole evaluation. The purpose of this section is to make sure the student can master the method of the application of the instruments and meters and improve the understanding of the theoretical courses. It is beneficial to the future project study and that can lay a foundation for it.

And the senior content is more important than the base. It takes about $60 \%$ of the whole evaluation. And it is the main content of the course. In this section the students should complete a whole research project. It contains the solution design, chip selection, implement hardware circuit, 
parameter's testing and so on. The students will take a whole year to complete the project. It needs the students make out a complete hardware work. And the evaluation content of this section includes the level of the difficulty, the innovation, the practical applicability, the completeness, and some other parameter demands.

\section{The effect of the new teaching mode}

In the spring semester of 2012, about 160 students were selected to attend the course. All of them were divided into some groups. There were about 3 or 4 students in a group. Any group should apply to join the innovation project built by the university. There were about 51 teams which have joined the project successfully. About 20 projects were named as national projects. And others were named as university projects.

A test was taken out in the end of the semester. All of them were requested to take part in the test. The exam content and examination mode are all the same. The contraction of the test result shows that the students who take part in the new teaching mode take well records. There were more students who take part in the new mode gained A in the test contrasting to the students who take part in the traditional teaching mode. And the students who take part in new teaching mode were better at discovering and solving the practical problem.

\section{Conclusion}

The practice for a semester shows that the new teaching mode has two advantages. First, the students can master the basic knowledge of the electronic technology application for the future study and innovation by the learning of basic experiment of the course. And the second, the practical ability and the sense of innovation can been approved by the learning of research experiment projects. The final purpose of this course is to lay a firm foundation for the learning of special field curse and the practice of innovation in the future. The new teaching mode is benefit to the solution of the follow problems. First, it is benefit to discover and train the elite talent. Second, it is help to the implementation of the elite talent education and to train the students' independent and autonomic learning. Third, it is help to the fully training and improvement of the students' engineering practical ability and the innovation ability. And finally, it is help to the implement of the outstanding engineer plans. The contrast in the end of the spring semester shows the priority of the new teaching mode for the elite education.

\section{REFERENCES:}

[1] Gu Ming-yuan, study and interpretation on state planning outline for medium and long-term education reform and development (2010-2020). journal of higher education. 2010(7): page 1-6 [2] Liu Hongwei, Ren Zhengyuan. the evaluation and the way of implementation of the higher education in the popular times. Modern University Education. 2009(4). Page: 13-17

[3] Wu Jianqiang, Li Yan, Qi Fengyan. the exploration and practice of the evaluation of the experiment teaching base on the open and independent mode. China University Teaching. 2011(4). Page 70-72

[4] Xu Pingping, Fan Xiaoqing, Gu Boquan. The construction and implement of the practice teaching system in the undergraduate business and economic field. Research in Higher Education of Engineering. 2010(s1). Page:1-4

[5] Li Mingyuan. The problems and improvement measures in the university experiment teaching. journal of higher education. 2009(4). Page: 50-52

[6] Lin Genjin. Investigation of experimental teaching with students' self-management. Research and exploration in laboratory. 2009(8). Page 148-150 